\title{
INTERESSE PÚBLICO: DISCURSO E PRÁTICA JORNALÍSTICA
}

\author{
Jaqueline Bartzen*
}

RESUMO: Jornalistas escolhem o tempo todo. Escolhem as palavras, o tom, o estilo, as fontes. E escolhem as notícias. No entanto, o discurso da profissão diz que toda notícia tem por ponto de partida o interesse público. Ao contrário: o jornalismo não parte de uma demanda social, mas se legitima a partir desse pressuposto. Esse artigo tem por objetivo analisar o sentido da produção da notícia (público-jornalista ou jornalista-público) e questionar o discurso jornalístico em contraposição à prática jornalística. Propõe-se três modelos de interesse: o de consumo, o público força-motora e o público entidade abstrata, que são discutidos segundo os conceitos de conotação e denotação, de Stuart Hall. A partir da revisão conceitual e da análise da prática jornalística, discute-se as implicações éticas do discurso jornalístico sobre o interesse público.

PALAVRAS-CHAVE: Discurso jornalístico; Interesse público; Ética.

\section{Apresentação da questão}

Na capa do jornal Gazeta do Povo de 3 de dezembro de 2006, domingo, uma foto e a chamada para o carderno Viver Bem: 'Beleza de mulheres curvilíneas'. Ao lado, 'Gazeta é primeiro jornal a vender anúncio em banca'. Abaixo, ocupando grande parte da metade inferior da capa, 'Livrarias estão desaparecendo das ruas de Curitiba'. As escolhas temáticas de notícias que preenchem as páginas de jornais e revistas ou ocupam o espaço da programação de radiojornais e telejornais, servem a determinados valores jornalísticos de seleção, dos quais os principais são a atualidade e o interesse público que o fato desperta.

Ciro Marcondes Filho, em $O$ Capital da Notícia, tem uma visão muito mais economicista de tais 'valores notícia', que, segundo o autor, servem a normas mercadológicas e são induzidos pela publicidade. "Notícia é informação transformada em mercadoria com 
todos os seus apelos estéticos, emocionais e sensacionais". De acordo com o autor, a escolha dos acontecimentos noticiáveis consiste em "separar a informação prática, ou seja, vendável, facilmente assimilável, do conjunto mais amplo de fatos e dados culturais". 2

A partir das premissas acima determinadas, Marcondes Filho propõe quatro características imprescindíveis para que uma notícia seja comercializável (vendida, consumida e aceita): generalização; padronização; simplificação e negação do subjetivismo. A estas, é possível acrescentar ainda a discurso acerca do interesse público, que justifica a necessidade do fazer jornalístico. A atividade é desenvolvida, segundos os profissionais costumam afirmar, como uma resposta à demanda social por informações que digam respeito a todos.

Ao se considerar válidos tais argumentos, é possível concluir que as chamadas de capa do jornal Gazeta do Povo, por exemplo, foram determinadas a partir dos anseios por informações dos leitores do veículo. O impresso, por si só, permite concluir que, de acordo com os jornalistas envolvidos na produção do conteúdo, existe um público no estado do Paraná (área de alcance do jornal) que tem interesse em informações sobre o próprio veículo, sobre beleza feminina ou sobre as livrarias em Curitiba. As premissas carregadas por estes profissionais, no momento da construção do conteúdo, vão ainda mais longe: acreditam que estes são os assuntos de maior relevância, em detrimento de tantos outros fatos não noticiados.

O discurso jornalístico está fundamentado sobre essa ótica. Os profissionais descrevem seu trabalho como um serviço prestado à população, uma demanda que surge da sociedade e que é suprida com o fornecimento de informação. Marcondes Filho traça um panorama oposto: o jornalista não produz 'sob encomenda', como faz supor a

\footnotetext{
* Jaqueline Bartzen é estudante do sexto período do curso de Comunicação Social, Habilitação em Jornalismo, da Universidade Federal do Paraná (UFPR).

${ }_{1}^{1}$ MARCONDES FILHO, Ciro. O capital da notícia. São Paulo: Ática, 1986. p. 13.

${ }^{2}$ MARCONDES FILHO, Ciro. O capital da notícia. São Paulo: Ática, 1986. p. $23-$ 24.
} 
noção de interesse público, mas desenvolve informações para então, posteriormente, atrair o leitor e convencê-lo a consumir.

$\mathrm{O}$ jornalista faz crer a existência de uma rede que começa no leitor (aquele que tem uma necessidade e pede por tê-la atendida); passa pelo profissional da comunicação (o 'instrumento', dotado de legitimidade para responder ao pedido da sociedade) e chega à informação (a qual só tem acesso o profissional legitimado). A lógica mercantil de Marcondes Filho leva à idéia de uma rede que funciona em sentido inverso: o jornalista produz tudo quanto deseja vender, trabalha os fatos de forma rentável e, por fim, entrega a notícia ao público final, que é levado a crer que pediu pelo 'produto' que consome.

A prática jornalística está, portanto, intimamente ligada à crença no interesse público. É a noção da existência de uma demanda social que justifica a atividade do jornalismo e que mascara o fato de que a notícia parte do jornalista, e não do leitor. A necessidade de informação não nasce do próprio público: é o profissional que decide o que o leitor quer.

Nesse contexto, cabe uma discussão sobre o conceito de interesse público: o que é e no que implica o interesse público? Que concepção jornalistas e público têm a respeito do interesse público? É o interesse público que faz o jornalismo ou é o jornalismo que determina e impõe o conteúdo de interesse público? Que responsabilidades éticas incidem sobre o profissional a partir de seu conhecimento ou desconhecimento do conceito (e do processo de construção do conceito)?

\section{Interesse público: revisão conceitual}

As incertezas com relação ao conceito de interesse público respondem pelas noções equivocadas que se tem do sentido da produção de notícia. Devido à força do discurso legitimador, o leitor não percebe que a notícia parte do jornalista e não de uma vontade 
pública geral. Sua percepção do jornalismo é de que a produção começa a partir da sociedade, a partir do interesse público.

Existe pouca discussão em torno do conceito e grande parte dela se concentra na área de Ciência Política. Em geral, o interesse público é entendido na comparação com o interesse privado ou invidual. Para Willian S. Minor, "o interesse privado funciona nas associações humanas que experimentam e controlam consequências de forma direta. Quando as consequências da associação humana não podem ser experimentadas e controladas diretamente, o interesse público é gerado".

R. A. Musgrave entende interesse público como a soma de interesses individuais, a partir da noção de eficiência do sistema econômico: "A satisfação do consumidor, sinônimo de interesse privado, era o padrão de eficiência do sistema econômico; tal eficiência representa o principal interesse público". ${ }^{4}$ Para Ernest S. Griffith, a palavra-chave à compreensão do conceito é bem-estar: "interesse público como manifesta na atividade governamental, mas com pleno reconhecimento de que numa sociedade pluralista isso constitui apenas um subtítulo, embora importante, do título mais amplo de 'bem-estar geral'". 5

Harold Lasswell tenta estabelecer uma definição que envolve empiricismo e objetivo final. "Por interesse comum se entende que num dado contexto social uma atividade específica tem efeitos de valores inclusivos (alfa), conforme verificado por processos estabelecidos de pesquisa (beta), que são compatíveis com o objetivo

3 MINOR, Willian S. O Interesse Público e o Compromisso Supremo. In: FRIEDRICH, Carl J. (Org.). O interesse público. Rio de Janeiro: Edições O Cruzeiro, 1967. p. 38.

${ }^{4}$ MUSGRAVE, R. A. O Interesse Público: Eficiência na Criação e na Manutenção do Bem-Estar Material. In: FRIEDRICH, Carl J. (Org.). O interesse público. Rio de Janeiro: Edições O Cruzeiro, 1967. p. 13.

5 GRIFFITH, Ernest S. Os Fundamentos Éticos do Interesse Público. In: FRIEDRICH, Carl J. (Org.). O interesse público. Rio de Janeiro: Edições O Cruzeiro, 1967. p. 26. 
da dignidade humana". ${ }^{6}$ A principal contribuição do autor, no entanto, diz respeito ao reconhecimento da ligação entre o interesse público e os processos decisórios. "Por interesse público entendemos que o interesse comum é suficientemente grande para garantir o uso de processos inclusivos de escolha ou decisão. Por interesse privado referimo-nos a efeitos de valor que são interesses comuns de magnitude insuficiente para garantir o uso de processos mais inclusivos do que exclusivos de escolha ou decisão".?

De acordo com o reconhecimento de Lasswell, transpõem-se as considerações ligadas à política para o campo jornalístico. Segundo o autor, o interesse público determina a decisão, a escolha. É, portanto, o agente legitimador de diversos processos, em várias áreas. Para C.W. Cassinelli, o interesse público é uma expressão da qual se valem políticos, funcionários públicos, jornalistas e professores da ciência política, mas para a qual não encontram uma definição. Segundo o autor, o conceito não existe em termos fechados de definição, mas aparece na prática: "quando uma ação é do interesse público, ela é digna de aprovação; quando não é do interesse público, merece nossa desaprovação". ${ }^{\circ}$

Cassinelli toca na questão central no que concerne à discussão a respeito do interesse público: embora não possa ser definido, ele existe e pode ser visualizado na prática de determinados grupos, os quais se valem de um discurso que envolva o conceito. É o que também afirmam Gerhard Colm e Horace M. Gray. Para o primeiro, "o termo (interesse público) se presta ao uso conveniente - em parte

${ }^{6}$ LASSWELL, Harold. O Interesse Público: Sugestões de Princípios de Conteúdo e Método. In: FRIEDRICH, Carl J. (Org.). O interesse público. Rio de Janeiro: Edições O Cruzeiro, 1967. p. 73.

${ }^{7}$ LASSWELL, Harold. O Interesse Público: sugestões de princípios de conteúdo e Método. In: FRIEDRICH, Carl J. (Org.). O interesse público. Rio de Janeiro: Edições O Cruzeiro, 1967. p. 74.

${ }^{8}$ CASSINELLI, C. W. O Interesse Público na Ética Política. In: FRIEDRICH, Carl J. (Org.). O interesse público. Rio de Janeiro: Edições O Cruzeiro, 1967. p. 54-55. 
porque resiste, por sua natureza, a uma definição precisa". 9 Já o segundo (citado por Roland Pennock), afirma que "o conceito de interesse público (...) tem validade e utilidade como um instrumento fictício para a ordenação dos negócios humanos, embora jamais consigamos defini-lo com precisão científica". ${ }^{10}$

A admissão da existência de um conceito sem definição que pode ser visualizado na prática social pressupõe a discussão de outras questões: o uso do discurso de interesse público na legitimação de determinadas atividades e as responsabilidades éticas dos profissionais que se valem de tal discurso. Esse tópico da questão pode ser sintetizado nas palavras de John D. Montgomery: o conceito de interesse público "oferece (...) a suprema justificativa ética de sacrifícios que o indivíduo pode ser chamado a fazer no interesse do Estado".

A transposição destas noções para o campo do jornalismo suscita o debate ético sobre a produção de notícias, apoiada no discurso legitimador do interesse público.

\section{Interesse público: diferentes noções no jornalismo}

Antes de se questionar o conceito de interesse público segundo a perspectiva jornalística, é preciso estabelecer uma diferenciação entre a prática jornalística, exercitada diariamente nas redações de veículos de comunicação, e o discurso jornalístico. Enquanto o primeiro diz respeito ao que efetivamente acontece, o segundo dá conta daquilo que deveria, e que se acredita ser, praticado.

${ }^{9}$ COLM, Gerhard. O Interesse Público: Chave Essencial da Política Pública. In: FRIEDRICH, Carl J. (Org.). O interesse público. Rio de Janeiro: Edições O Cruzeiro, 1967. p. 122.

${ }^{10}$ PENNOCK, Roland. A Unidade e a Multiplicidade: Uma Observação Sobre o Conceito. In: FRIEDRICH, Carl J. (Org.). O interesse público. Rio de Janeiro: Edições O Cruzeiro, 1967. p. 187.

11 MONTGOMERY, John D. O interesse Público nas Ideologias do Desenvolvimento Nacional. In: FRIEDRICH, Carl J. (Org.). O interesse público. Rio de Janeiro: Edições O Cruzeiro, 1967. p. 219-220. 
O discurso jornalístico fundamenta a notícia em dois pilares: atualidade e interesse público. A prática jornalística, no entanto, apóia-se em dois outros fatores: tempo e espaço. $\mathrm{O}$ discurso levado à prática implicaria no questionamento (e possíveis pesquisas comprobatórias) sobre os desejos de informação do leitor antes do início do processo de produção. Ou seja, antes mesmo da produção de matérias, durante a elaboração da pauta, o jornalista deveria analisar a pertinência de cada assunto segundo o interesse público.

No entanto, nota-se a ausência de tal preocupação no exercício prático da atividade. $\mathrm{O}$ acelerado ritmo de trabalho, imposto pela pressão do deadline (prazo final de conclusão da matéria), e a preocupação com o espaço que precisa ser preenchido (páginas em impressos, minutos em rádio e televisão) ${ }^{12}$ não deixam espaço para a convergência entre o discurso e a prática jornalísticos.

A partir dessa diferenciação, é possível estabelecer noções diversas para o próprio conceito de interesse público. O discurso jornalístico propõe a existência do interesse público enquanto força motora, ou seja, ponto de partida do processo de produção jornalística. O interesse público força-motora diz respeito a toda informação da qual prescinda ou a qual deseje a sociedade (não necessariamente a totalidade dos grupos sociais). Não há, no entanto, uma definição fechada, uma proposta conclusiva, ou mesmo estudos e pesquisas que comprovem a existência dessa motivação da produção jornalística.

A prática jornalística revela, porém, a inexistência do interesse público segundo proposto pelo discurso. A crença na existência do interesse público força-motora faz nascer um outro interesse público: uma entidade abstrata que legitima as escolhas do jornalista, e a própria necessidade da existência do jornalismo. O interesse público entidade-abstrata compreende valores que surgem durante a atividade prática e que não dependem, diretamente, das pessoas envolvidas no processo produção-consumo de notícias. Não é determinado pelos meios de comunicação ou pelos profissionais de comunicação, nem

${ }^{12}$ Exceção: jornalismo on-line. 
pelo público. Não depende individualmente de ninguém, mas também não é fruto de uma discussão coletiva. Não é determinado por estruturas fixas e, portanto, se modifica com as mudanças sociais advindas com o passar do tempo.

É o interesse público entidade-abstrata, desdobramento do inexistente interesse público força-motora, que gera a certeza do consumidor sobre a idoneidade do jornalista e do jornal e que, portanto, fornece subsídios para a relação de confiança que favorece a compra da matéria. Mas, embora a legitimidade do processo seja um dos fatores que determinam o consumo, há que se considerar que esta não é a única motivação que leva o leitor a procurar informação. Existe sim um impulso que parte do consumidor em direção à notícia, mesmo que não seja esse impulso o ponto de partida da matéria, como faz crer a noção de interesse público força-motora.

Não se pode negar que esse impulso seja uma demonstração do interesse do público. No entanto, é importante destacar que essa motivação diz respeito ao próprio sistema social no qual o indivíduo está inserido, ou seja, a necessidade de informação é comum àqueles que vivem em sociedades nas quais a comercialização (inclusive de informação) é central. Assim, é importante perceber que o interesse do público não implica em interesse público (tanto força-motora, quanto entidade-abstrata). Esse impulso é interesse de consumo, próprio do sistema social.

É possível, então, distinguir três tipos de interesse: o de consumo (próprio da sociedade e que justifica a procura do consumidor por informação); o público força-motora (que não existe da forma como é descrito pelo discurso jornalístico, mas que gera o terceiro tipo de interesse); e o público entidade-abstrata (que legitima as escolhas do jornalista). Os três tipos de interesse se mesclam num processo complexo de abstração capaz de enevoar os meandros da produção de notícia e fortalecer o discurso do jornalismo enquanto campo de missão nobre.

Em uma sistematização simples, é possível afirmar que existe um interesse de consumo real, que é distorcido e convertido (no 
discurso) em interesse público força-motora, que por sua vez é distorcido e convertido (na prática) em interesse público entidadeabstrata. $\mathrm{O}$ interesse público entidade-abstrata, então, legitima o processo todo, por meio da transmissão da idéia de real existência do interesse público força-motora.

Segundo os conceitos de conotação e denotação de Stuart Hall, pode-se dizer que o interesse de consumo é uma denotação que gera uma conotação: o interesse público força-motora. Este gera outra conotação: o interesse público entidade-abstrata. A função desse último é fazer com que o conotado interesse público força-motora apresente-se como denotado, ou seja, como expressão do real. De acordo com o autor, uma denotação apresentada como conotação implica em ideologia.

\section{Interesse público: discussão ética no jornalismo}

Tanto os processos ideológicos de conotação e denotação, quanto os valores que compõem a entidade abstrata interesse público (último produto do processo) são desconhecidos não apenas do público, mas também dos próprios jornalistas. Isso não apenas porque as composições são complexas, mas também porque pouco se pesquisa, se reflete ou se discute sobre as noções de interesse público.

A alienação do jornalista com relação ao processo não faz dele um ator diretamente desonesto, o que também não implica no extremo oposto: a vitimização do profissional. Mesmo sendo o interesse público uma construção abstrata sobre a qual os implicados no processo não exercem controle direto, são inegáveis as contribuições que o desconhecimento traz para a legitimação e manutenção da produção da notícia tal qual a atual configuração. Assim, o jornalista não pode ser visto como vítima inocente, já que também está envolvido no desenrolar da ideologia e dela tira proveito.

Não se pode dizer que o jornalista seja responsável pela reprodução de determinada ideologia, mas o profissional responde 
diretamente pelo processo do qual faz parte, ou seja, se ele desconhece os meandros da produção de notícia, é também um gerador da alienação do leitor, promovida a partir do discurso de interesse público. Ao mesmo tempo em que o jornalista não é culpado, também não é mera vítima, já que tem obrigação ética sobre sua própria atividade.

A partir destes reconhecimentos, levanta-se a discussão da ética jornalística na construção de matérias e propagação da informação. O profissional declara, no discurso jornalístico, que a produção da notícia acontece a partir do público, mas, durante a prática jornalística, verifica-se o contrário: a notícia começa no jornalista, que depois a vende a um público e o faz crer que atendeu a um pedido. $\mathrm{O}$ profissional tem responsabilidades morais que $\mathrm{o}$ impedem de não ter consciência das contradições entre a prática jornalística e o discurso jornalístico no que concerne o interesse público. E se tiver, seus deveres éticos são ainda maiores.

\section{BIBLIOGRAFIA}

CASSINElli, C. W. O Interesse Público na Ética Política. In: FRIEDRICH, Carl J. (Org.). O interesse público. Rio de Janeiro: Edições O Cruzeiro, 1967.

COLM, Gerhard. O Interesse Público: Chave Essencial da Política Pública. In: FRIEDRICH, Carl J. (Org.). O interesse público. Rio de Janeiro: Edições O Cruzeiro, 1967.

GRIFFITH, Ernest S. Os Fundamentos Éticos do Interesse Público. In: FRIEDRICH, Carl J. (Org.). O interesse público. Rio de Janeiro: Edições O Cruzeiro, 1967.

HALL, Stuart. Da diáspora: identidades e mediações culturais. Belo Horizonte: Editora UFMG, 2003.

LASSWELL, Harold. O Interesse Público: Sugestões de Princípios de Conteúdo e Método. In: FRIEDRICH, Carl J. (Org.). O interesse público. Rio de Janeiro: Edições O Cruzeiro, 1967. 
MARCONDES FILHO, Ciro. O capital da notícia. São Paulo: Ática, 1986.

MINOR, Willian S. O Interesse Público e o Compromisso Supremo. In: FRIEDRICH, Carl J. (Org.). O interesse público. Rio de Janeiro: Edições O Cruzeiro, 1967.

MONTGOMERY, John D. O interesse Público nas Ideologias do Desenvolvimento Nacional. In: FRIEDRICH, Carl J. (Org.). $O$ interesse público. Rio de Janeiro: Edições O Cruzeiro, 1967.

MUSGRAVE, R. A. O Interesse Público: Eficiência na Criação e na Manutenção do Bem-Estar Material. In: FRIEDRICH, Carl J. (Org.). O interesse público. Rio de Janeiro: Edições O Cruzeiro, 1967.

PENNOCK, Roland. A Unidade e a Multiplicidade: Uma Observação Sobre o Conceito. In: FRIEDRICH, Carl J. (Org.). $O$ interesse público. Rio de Janeiro: Edições O Cruzeiro, 1967. 